\title{
The Effect of Systemic Chemotherapy on Ovarian Function: A Prospective Clinical Trial
}

Filiz Çelebi ${ }^{1}$ (1), Çetin Ordu² (1), Serkan Ilgün ${ }^{3}$ (1), Alper Öztürk ${ }^{4}$ (1), Zeynep Erdoğan Iyigün ${ }^{5}$ (1), Gül Alço ${ }^{6}$ (1), Tomris Duymaz ${ }^{7}$ (D), Fatma Aktepe ${ }^{8}$ (D), Gürsel Soybir ${ }^{9}$ (D), Bülent Baysal ${ }^{10}$ (D), Vahit Özmen ${ }^{11}$ (D)

${ }^{1}$ Department of Radiology, Gayrettepe Florence Nightingale Hospital, İstanbul, Turkey

${ }^{2}$ Department of Oncology, Gayrettepe Florence Nightingale Hospital, İstanbul, Turkey

${ }^{3}$ Department of General Surgery, Demiroğlu Bilim University School of Medicine, İstanbul, Turkey

${ }^{4}$ Department of General Surgery, Biruni University Hospital, İstanbul, Turkey

${ }^{5}$ Department of Physical Therapy and Rehabilitation, Demiroğlu Bilim University School of Medicine, İstanbul, Turkey

${ }^{6}$ Department of Radiation Oncology, Gayrettepe Florence Nightingale Hospital, İstanbul, Turkey

${ }^{7}$ Department of Physical Therapy and Rehabilitation, Bilgi University, İstanbul, Turkey

${ }^{8}$ Department of Pathology, Gayrettepe Florence Nightingale Hospital, İstanbul, Turkey

${ }^{9}$ Department of General Surgery, Memorial Etiler Hospital, İstanbul, Turkey

${ }^{10}$ Department of Obstetrics and Gynecology, İstanbul Florence Nightingale Hospital, İstanbul, Turkey

${ }^{11}$ Department of General Surgery, İstanbul Florence Nightingale Hospital, İstanbul, Turkey

\section{ABSTRACT}

Objective: Premenopausal women with breast cancer are at risk of developing ovarian failure after chemotherapy. The aim of this study was to investigate the negative effects of systemic chemotherapy on ovarian function in premenoupausal women with breast cancer.

Materials and Methods: Thirty-one premenopausal women with operable breast cancer aged between 26-48 years were enrolled in this prospective cohort study to investigate preliminary results. Additional 69 patients' data will be included after the completion of all five measurements. The change in serum Antimullerian Hormone (AMH) levels, mean ovarian volumes (MOV) and antral follicle counts (AFCs) at 3-month intervals were recorded to evaluate ovarian function. Women who had at least one pretreatment and four post-treatment measurements in one year follow-up period were included in the study. Decision of chemotherapy regimen was taken by the Tumor Board.

Results: Thirty-one patients had all five $\mathrm{AMH}, \mathrm{MOV}$ and $\mathrm{AFCs}$ results. There was a statistically significant negative correlation between $1^{\text {st }}-5^{\text {th }} \mathrm{AMH}$ levels $(\mathrm{p}=0.006)$ and $1^{\text {st }}-5^{\text {th }}$ AFCs during the follow-up period $(\mathrm{p}<0.0001)$. However pre- and post-chemotherapy measurements of MOVs did not demonstrate any significant correlation ( $\mathrm{p}=0.799)$. BMI, parity, lactation, histopathology and molecular subtypes of breast cancer, alcohol intake, smoking and type of chemotherapy regimen were not significantly correlated with $\mathrm{AMH}, \mathrm{AFC}$ and MOV.

Conclusion: Pretreatment AMH levels and AFC were shown to have a significant role in early prediction of ovarian-reserve after chemotherapy.

Keywords: AMH, ovarian reserve, breast cancer, chemotherapy

Cite this articles as: Çelebi F, Ordu Ç, İlgün S, Öztürk A, Erdoğan İyigün Z, Alço G, et al. The Effect of Systemic Chemotherapy on Ovarian Function: A Prospective Clinical Trial. Eur J Breast Health 2020; 16(3): 177-182

\section{Introduction}

Breast cancer is the most common malignancy in women, and the incidence increases with age. The majority of breast cancer patients (75\%) are postmenopausal, and about $7 \%$ are diagnosed before the age of 40 in developed countries (1). In Turkey, 45\% of patients with breast cancer are premenopausal, and $20 \%$ are underage of 40 years (2). Most premenopausal women with breast cancer receive cytotoxic chemotherapy and there is an increased risk of ovarian failure (3). Gonadal suppression and ovarian failure manifests as early onset of menopause, chemotherapy-related amenorrhea and infertility $(4,5)$.

Since direct measurement of ovarian-reserve is difficult, it is usually determined as the number of non-growing follicles in the ovaries (6, 7). Antral follicle count, follicle stimulating hormone (FSH), inhibin and antimullerian hormone (AMH) levels are also used to estimate ovarian-reserve $(7,8)$. FSH and inhibin indirectly represent ovarian- reserve, but the changes in their levels during the ovarian cycle make the estimation difficult. Although counting antral follicles by ultrasonography is the most effective method, it depends on physician's experience, time consuming and also more expensive than blood tests (9).

It has been showed that, the Gonadotropin-releasing hormone (GNRH )analogs combined with chemotherapy decrease the rate of ovarian failure in the patients with HR negative breast cancer (10). In the other publications limited number of patients with HR positive breast cancer, it's thought that the combined therapy also decreases the rates of ovarian failure (11). 
This protective effect of GNRH analogs may occur with indirect or direct impacts. In indirect impact it may lead the ovaries to the situation like as in silent and prepubertal term that makes them less sensitive to chemotherapeutic agents. In direct impact it may prevent the ovaries damaged by chemotherapy through intracellular pathways leading the receptors on follicle cells (12).

Although there is an initial decrease in the level of AMH with the effect of GNRH followed by an increase, there are hypotheses supporting that the sudden decrease in AMH levels is independent of the effect of GNRH analogues (13). AMH is the best biomedical marker for ovarian function and to be an early and sensitive plasma marker after chemotherapy for the evaluation of ovarian- reserve (14). There are limited data demonstrating the long term effect of chemotherapy on AMH levels in premenopausal breast cancer patients (15).

Determination of dysfunction of ovaries due to chemotherapy is very important for patients with breast cancer who want to maintain fertilization (16). The predictive value of factors that determine ovarianreserve before and after chemotherapy, such as AMH, AFC and MOV, should be determined. In this way the fertility preservation of patients can be predicted. Knowing that the ovarian failure causes problems such as osteoporosis in the postmenopausal period by Henry et al. (14).

In this study, we investigated the negative effects of systemic chemotherapy on ovarian function in premenopausal women with breast cancer.

\section{Materials and Methods}

Between April 2015 and November 2016, 31 premenopausal women with breast cancer were enrolled in this prospective cohort study to investigate preliminary results. Additional 69 patients' data will be included after all five measurements completed in an attempt to reach 100 patients as planned at the beginning of the study. Local ethic committee approval was obtained and all subjects were recruited to the study after giving informed consent. AMH levels, antral follicle counts and ovarian volumes were recorded before chemotherapy. Serum AMH levels, mean ovarian volumes and antral follicle counts at 3 months intervals were measured. Demographic information and clinical data (surgical methods, tumor histopathology and molecular subtypes, hormone receptor status including estrogen, progesterone and human epidermal growth factor receptor-2 (HER2) and chemotherapy regimens) were collected from the database.

Patients with a history of other malignancy and prior chemotherapy or pelvic radiation, bilateral oophorectomy and hysterectomy were excluded.

Chemotherapy regimens were described as adriamycin and cyclophosphamide (AC), docetaxel-cyclophosphamide (TC), of anthracycline-cyclophosphamide and taxanes $(\mathrm{AC}+\mathrm{T})$ given sequentially, 5-fluorouracil-epirubicin- cyclophosphamide (FEC), FEC and taxanes $(\mathrm{FEC}+\mathrm{T})$.

There are 23 patients with Luminal type breast cancer, which are hormone receptor-positive included in the study. The patients with hormone receptor-positive breast cancer had adjuvant hormone therapy with selective oestrogen receptor modulators (SERMs) with/without ovarian suppression (e.g., tamoxifen \pm LHRH-analogues). The given GNRH analogues. AMH levels were measured using enzymelinked immunosorbent assay (ELISA). AMH assays were performed by USCN Life Science, Inc (Buckingham, UK).

Transvaginal ultrasonography (EV9-4 probe, Siemens Acuson S2000, Erlangen, Germany) was performed to determine ovarian volume and AFC by an expert obstetrician in assisted reproductive techniques (ART) and the images were evaluated with a radiologist experienced in women's imaging. Mean ovarian volume (MOV) was calculated with the use of this formula ( $\mathrm{A} \times \mathrm{B} \times \mathrm{C} \times 0.52)$. AFC was determined as the number of follicles $2-10 \mathrm{~mm}$ in average diameter for both ovaries. AFC recorded as sum of antral follicles counted from both ovaries. Transvaginal sonograpy was preferred as a standard method. But for one patient transabdominal sonography was used due to her preference.

\section{Statistical analysis}

Variables are given as mean \pm standard deviations. Median and minimum-maximum were calculated unless otherwise specified. The distribution of variables was analysed with Kolmogorov-Smirnov Test and the quantitative analysis of variables was done with chi-square test.

Pearson test was used to calculate the correlation between $\mathrm{AMH}$, $\mathrm{MOV}$ and AFCs. A p value less than 0.5 was considered to indicate a significant difference. For all statistical analyses, IBM Statistical Package for the Social Sciences software, version 20.0 (IBM SPSS corp.; Armonk, NY, USA) was used.

\section{Table 1. Histopathological characteristics of patients}

$\begin{array}{lc}\text { Characteristics } & \text { Number of patients } \\ \text { Histopathology } & 25 \\ \text { Invasive ductal ca } & 6 \\ \text { Others } & \\ \text { Molecular subtypes } & 3 \\ \text { Luminal A } & 20 \\ \text { Luminal B } & 5 \\ \text { TNBC } & 3 \\ \text { HER-2 positive } & \\ \text { Stage } & \\ \text { I } & 6 \\ \text { II } & 21 \\ \text { III } & 4 \\ \text { Grade } & \\ \text { I-II } & 11 \\ \text { III } & 20 \\ \text { SLNB } & 26 \\ \text { ALNB } & 14 \\ \text { Unifocal } & 22 \\ \text { Multifocal-multiscentric } & \\ \text { HER2: Human epidermal growth factor receptor-2; SLNB: Sentinel lymph } \\ \text { node biopsy; ALNB: Axillary lymph node biopsy }\end{array}$


Table 2. Chemotherapy regimens and number of patients

\section{Chemotherapy regimen}

Adriamycin and cyclophosphamide (AC)

Docetaxel-cyclophosphamide (TC)

Anthracycline-cyclophosphamide + taxanes $(A C+T)$

5-fluorouracil-epirubicin- cyclophosphamide (FEC)

5-fluorouracil-epirubicin- cyclophosphamide (FEC) + taxanes
Number of patients (n)

13

3

11

1

1

\section{Cycles (n)}

4 cycles AC

4 cycles TC

4 cycles $A C+4$ cycles $(A C+T)$

6 cycles FEC

6 cycles FEC+ 3 cycles taxanes
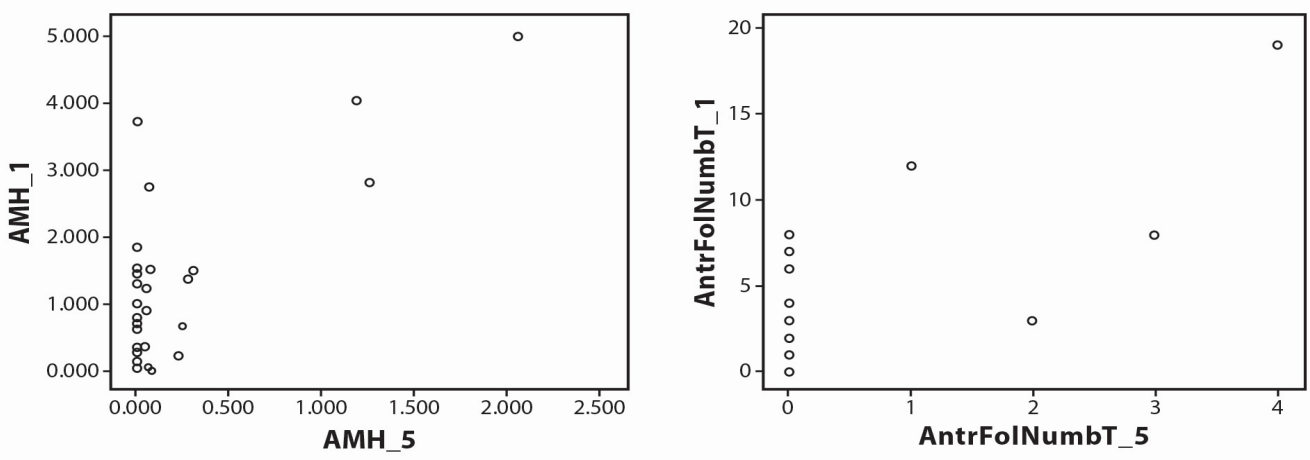

Figure 1. There is statistically significant correlation between $1^{\text {st- }-5^{\text {th }}}$ AMH levels $(p=0.006), A F C s$ showed statistically significant correlation between $1^{\text {st }-5^{\text {th }}}$ measures during follow-up period $(p<0.0001)$
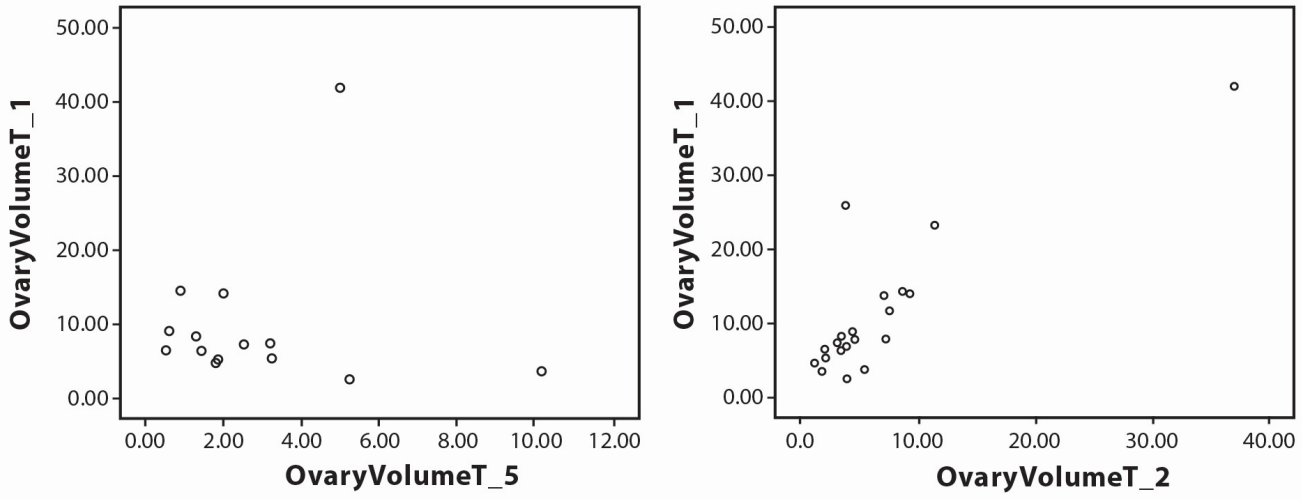

Figure 2. There is minimal negative correlation between MOV measures between $1^{\text {st- }-5^{\text {th }}}$ measures between $1^{\text {st- }} 5^{\text {th }}$ measures and this can represent reversal of ovarian volumes to the initial values $(r=-0.49, p=0.799)$

\section{Results}

Thirty-one patients with median age of 38 years (range: 26-48) were included in the study. Histopathologic characteristics of the study population are shown in Table 1.

BMI score was 30.8\% normal (19-24), 46.2\% overweight (24-29) and $23.1 \%$ obese (29-33). $25.8 \%$ of the patients were smokers.

Thirty-one patients had all five AMH, MOVs and AFCs results and the results were recorded prospectively. Initial serum AMH levels, AFCs and MOVs were compared with $2^{\text {nd }}, 3^{\text {rd }}, 4^{\text {th }}$ and $5^{\text {th }}$ values. All measures of ovarian reserve showed acute impairment after chemotherapy. AMH levels decreased sharply and rapidly.
There was a statistically significant correlation between $1^{\text {st }}-5^{\text {th }} \mathrm{AMH}$ levels $(\mathrm{p}=0.006)$. Conversely, there was no association between $1^{\text {st }}-2^{\text {nd }}$ $(\mathrm{p}=0.976), 1^{\text {st }}-3^{\text {rd }}(\mathrm{p}=0.076)$ and $1^{\text {st }}-4^{\text {rd }}$ results $(\mathrm{p}=0.065)$. The recovery of AMH levels showed renewal of follicle growth after therapy (Figure 1).

AFCs showed a statistically significant correlation between the $1^{\text {st }}-5^{\text {th }}$ measurements during the follow-up period $(\mathrm{p}<0.0001)$ (Figure 1).

There was a minimal negative correlation between MOV measurements between the $1^{\text {st }}-5^{\text {th }}$ measurements and this could represent reversal of ovarian volumes to the initial values $(r=-0.49, \mathrm{p}=0.799)$ (Figure 2$)$.

Prechemotherapy AMH, MOV and AFCs showed a statistically significant negative correlation with age (the values were measured respec- 

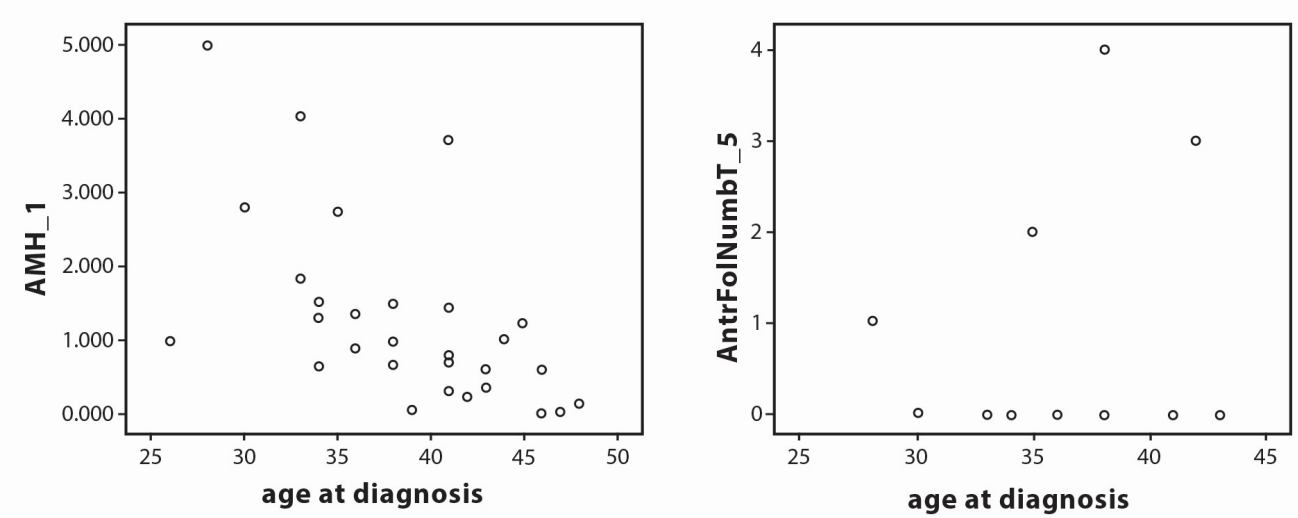

Figure 3. $1^{\text {st }} \mathrm{AMH}$ and AFCs showed statistically significant negative negative correlation with the age (The values were measured respectively, $r=-0.507, p=0.004 ; r=-0.401, p=0.025)$. Also there is significant negative correlation between $5^{\text {th }} A M H$ level and age $(r=-0.505, p=0.004)$
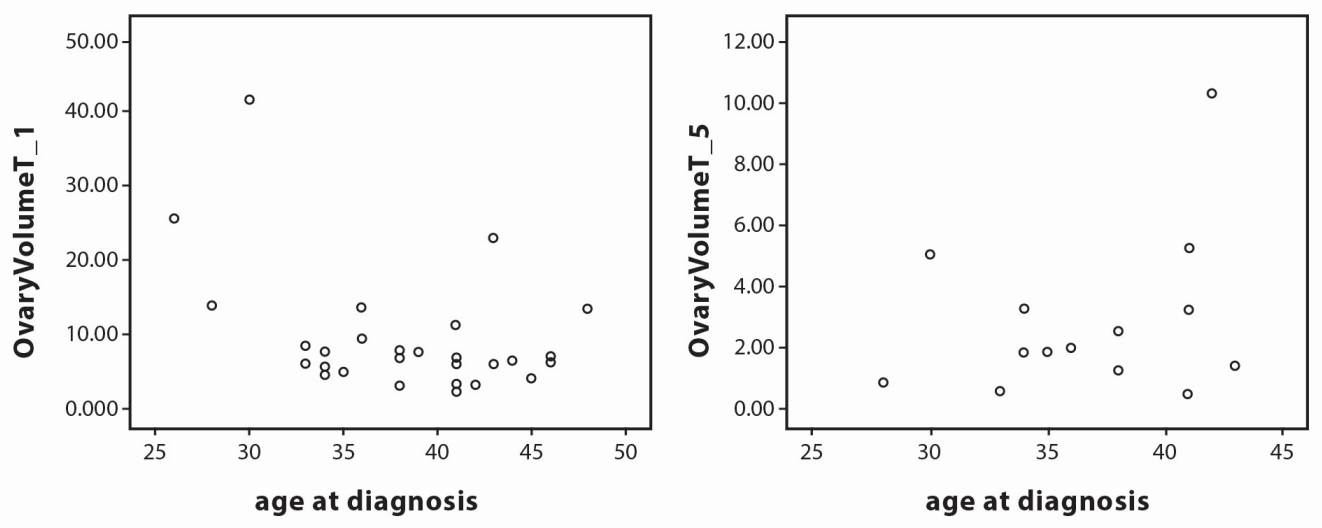

Figure 4. $1^{\text {st }}$ MOV showed statistically significant negative correlation with the age $(r=-0.429, p=0.016)$. Also there is a significant negative correlation between $5^{\text {th }}$ MOV level and age

tively as $\mathrm{r}=-0.507, \mathrm{p}=0.004 ; \mathrm{r}=-0.429, \mathrm{p}=0.016 ; \mathrm{r}=-0.401, \mathrm{p}=0.025)$. There was also a significant negative correlation between the $5^{\text {th }} \mathrm{AMH}$ level and age ( $\mathrm{r}=-0.505, \mathrm{p}=0.004)$ (Figure 3, 4).

Chemotherapy regimens and number of patients were described in Table 2. There was no significant difference $(p>0.05)$ between the effects of adriamycin-cyclophosphamide, docetaxel-cyclophosphamide and adriamycin-cyclophosphamide-taxane on AFC, MOV and $\mathrm{AMH}$ values.

BMI, parity, lactation, histopathology and moleculary subtypes of breast cancer, alcohol intake and smoking were not found to be significantly correlated with AMH, AFC and MOV.

\section{Discussion and Conclusion}

Cancer treatments have adverse effects on female reproductive function due to damage to the ovarian follicles and increase the risk of infertility (17). Future fertility and treatment management are important factors for young women and better methods are needed to predict long term ovarian reserve in individual patients $(18,19)$.

Many prospective studies in breast cancer patients have mentioned the importance of predicting chemotherapy-induced amenorrhea. Some studies have shown that pretreatment AMH levels predict ovarian-
Anderson and Cameron (23) showed that AMH levels before adjuvant chemotherapy predicts long term ovarian reserve. Ruddy et al. (24) concluded that AMH, E2 and FSH are promising methods to determine amenorrhea and ovarian reserve. Our results are in concordance with these studies and a statistically significant correlation between pre and post chemotherapy AMH levels was found.

Our data showed a significant association between AFC results. Pretreatment AFC was strongly negatively correlated with the $5^{\text {th }}$ measurements. Similar to our work, in a recently published trial by Wenners et al. (25), AMH, OFC and MOV values were recorded at baseline and at 6-month intervals with a total of 51 patients. AMH and OFC values at the end of the $1^{\text {st }}$ year were significantly different from baseline, but there was no significant difference in MOV values.

Age-related $\mathrm{AMH}, \mathrm{AFC}$ and $\mathrm{MOV}$ values were found to be higher in younger patients in our study, in accordance with the literature. Therefore, preservation against dysfunction for continuation of fertility may not be necessary in patients with higher $\mathrm{AMH}$ and $\mathrm{AFC}$ values below a certain age. Patients with a post-chemotherapy high percentage of reserve (AMH, OFC) and with younger age may not need fertility preservation. In our study, it was determined that the over-reserve was preserved in patients with younger age and who had high pre-chemotherapy $\mathrm{AMH}$ and AFC values, but the number of patients and the follow-up period were limited and insufficient to determine threshold values. 
It could not be determined which chemotherapy regimen more adversely affected ovarian-reserve for discontinuation of fertility. Although there is no data in the literature, it was not possible to derive this result from our study due to the heterogenity of the chemotherapy regimens.

$\mathrm{AMH}, \mathrm{AFC}$ and MOV values were followed in pre- and post chemotherapy periods for 6 month or 1 year intervals in the literature. In our study 31 patients were followed up with intervals of 3 months and the values acquired at the end of the first year were significantly similar with the literature. One of the consequences of this study is the importance of determining initial pre-chemotherapy and end of $1^{\text {st }}$ post-chemotherapy year AFC and AMH values for the possibility of predicting over-reserve, as in the literature by Wenners et al. (25).

Our study has several strengths, including that recall rates were minimized by the prospective design.

In conclusion, pretreatment AMH levels and AFC were shown to have a significant role in the early prediction of ovarian reserve after chemotherapy. The present analyses have several limitations, such as the number of patients included, and further studies with longer followup and a larger study population are needed in order to determine regimen-based results of chemotherapy on AMH levels and antral follicle counts.

Ethics Committee Approval: Ethics committee approval was received for this study from the ethics committee of Istanbul Bilim University (04.07.2017/608).

Informed Consent: Written informed consent was obtained from patients who participated in this study.

Peer-review: Externally peer-reviewed.

Author Contributions: Concept - F.Ç., S.İ.; Design - A.Ö., Z.E.; Supervision - V.Ö., B.B.; Resources - F.Ç., A.Ö.; Materials - B.B.; Data Collection and/or Processing - B.B., G.A.; Analysis and/or Interpretation - F.A., G.S.; Literature Search - Ç.O.; Writing Manuscript - F.Ç., Ç.O.; Critical Review - V.Ö.

Acknowledgements: The author wish to acknowledge David Chapman for language editing.

Conflict of Interest: The authors have no conflicts of interest to declare.

Financial Disclosure: The author declared that this study has received no financial support.

\section{References}

1. Brinton LA, Sherman ME, Carreon JD, Anderson WF. Recent Trends in Breast Cancer Among Younger Women in the United States. J Natl Cancer Inst 2008; 100: 1643-1648. (PMID: 19001605) [CrossRef]

2. Özmen V. Breast Cancer in Turkey: Clinical and Histopathological Characteristics (Analysis of 13.240 Patients). J Breast Health 2014; 10: 98105. (PMID: 28331652) [CrossRef]

3. de Pedro M, Otero B, Martin B. Fertility Preservation and Breast Cancer: A Review. Ecancermedicalscience 2015; 9: 503. (PMID: 25729416) [CrossRef]

4. Yu B, Duglas N, Ferin MJ, Nakhuda GS, Crew K, Lobo RA, Hershman DL. Changes in Markers of Ovarian Reserve and Endocrine Function in Young Women with Breast Cancer Undergoing Adjuvant Chemotherapy. Cancer 2010; 116: 2099-2105. (PMID: 20187091) [CrossRef]
5. Dunlop CE, Anderson RA. Uses of Anti-Müllerian Hormone (AMH) Measurement Before and After Cancer Treatment in Women. Maturitas 2015; 80: 245-250. (PMID: 25596814) [CrossRef]

6. Kim HA, Seong MK, Kim JH, Kim YG, Choi HS, Kim JS, Park IC, Jin HO, Lee JK, Noh WC. Prognostic Value of Anti-Müllerian Hormone and inhibin B in Patients with Premenopausal Hormone Receptor-positive Breast Cancer. Anticancer ResMar 2016; 36: 1051-1057.

7. Iliodromiti S, Nelson SM. Biomarkers of Ovarian Reserve. Biomark Med 2013; 7: 147-158. (PMID: 23387496) [CrossRef]

8. Steiner AZ. Biomarkers of Ovarian Reserve as Predictors of Reproductive Potential. Semin Reprod Med 2013; 31: 437-442. (PMID: 24101224) [CrossRef]

9. Holte J, Brodin T, Berglund L, Hadziosmanovic N, Olovsson M, Bergh T. Antral follicle counts are strongly associated with live-birth rates after assisted reproduction with superior treatment outcome in women with polycystic ovaries. Fertil Steril 2011; 96: 594-599. (PMID: 21880276) [CrossRef]

10. Moore HC, Unger JM, Phillips KA, Boyle F, Hitre E, Porter D. Goserelin for ovarian protection during breast-cancer adjuvant chemotherapy. $\mathrm{N}$ Engl J Med 2015; 372: 923-932. (PMID: 25738668) [CrossRef]

11. Del Mastro L, Boni L, Michelotti A, Gamucci T, Olmeo N, Gori S, Giordano M, Garrone O, Pronzato P, Bighin C, Levaggi A, Giraudi S, Cresti N, Magnolfi E, Scotto T, Vecchio C, Venturini M. Effect of the gonadotropin-releasing hormone analogue triptorelin on the occurrence of chemotherapy-induced early menopause in premenopausal women with breast cancer: a randomized trial. JAMA 2011; 306: 269-276 (PMID: 21771987) [CrossRef]

12. Lambertini M, Campbell C, Bines J, Korde LA, Izquierdo M, Fumagalli D, Del Mastro L, Ignatiadis M, Pritchard K, Wolff AC, Jackisch C, Lang I, Untch M, Smith I, Boyle F, Xu B, Barrios CH, Baselga J, Moreno-Aspitia A, Piccart M, Gelber RD, de Azambuja E. Adjuvant Anti-HER2 Therapy, Treatment-Related Amenorrhea, and Survival in Premenopausal HER2-Positive Early Breast Cancer Patients. J Natl Cancer Inst 2019; 111: 86-94. (PMID: 29878225) [CrossRef]

13. Hasky N, Uri-Belapolsky S, Goldberg K, Miller I, Grossman H, Stemmer SM, Ben-Aharon I, Shalgi R. Gonadotrophin-releasing hormone agonists for fertility preservation: unraveling the enigma? Hum Reprod 2015; 30 : 1089-1101. (PMID: 25796551) [CrossRef]

14. Henry NL, Xia R, Schott AF, McConnel D, Banerjee M, Hayes DF. Prediction of postchemotherapy ovarian function using markers of ovarian reserve. Oncologist 2014; 19: 68-74. (PMID: 24319018) [CrossRef]

15. Van Rooij IA, BroekmansFJ, Scheffer GJ, Looman CW, Habbema JD, de Jong FH, Fauser BJCM, Themmen APN, te Velde ER. Serum antimullerian hormone levels best reflect the reproductive decline with age in normal women with proven fertility: A longitudinal study. Fertil Steril 2005; 83: 979-987. (PMID: 15820810) [CrossRef]

16. Lee SJ, Schover LR, Partridge AH, Patrizio P, Wallace WH, Hagerty K, Beck LN, Brennan LV, Oktay K, American Society of Clinical Oncology. American Society of Clinical Oncology recommendations on fertility in cancer patients. J Clin Oncol 2006; 24: 2917-2931. (PMID: 16651642) [CrossRef]

17. Dillon KE, Sammel MD, Prewitt M Ginsberg JP, Walker D, Mersereau JE, Gosiengfiao Y, Gracia CR. Pretreatment antimüllerian hormone levels determine rate of posttherapy ovarian reserve recovery: acute changes in ovarian reserve during and after chemotherapy. Fertil Steril 2013; 99: 477-483. (PMID: 23084267) [CrossRef]

18. Faddy MJ, Gosden RG, Gougeon A, Richardson SJ, Nelson JF. Accelerated disappearance of ovarian follicles in mid-life: implications for forecasting menopause. Hum Reprod 1992; 7: 1342-1346. (PMID: 1291557) [CrossRef]

19. Ethics Committee of the American Society for Reproductive Medicine. Fertility preservation and reproduction in cancer patients. Fertil Steril 2005; 83: 1622-1628. (PMID: 15950628) [CrossRef]

20. Anders C, Marcom PK, Peterson B, Gu L, Unruhe S, Welch R, Lyons P, Behera M, Copland S, Kimmick G, Shaw H, Snyder S, Antenos M, Woodruff T, Blackwell K. A pilot study of predictive markers of chemo- 
therapy-related amenorrhea among premenopausal women with early stage breasr cancer. Cancer Invest 2008; 26: 286-295. (PMID: 18317970) [CrossRef]

21. Bozza C, Puglisi F, Lambertini M, Osa EO, Manno M, Del Mastro L. Anti-Mullerian hormone: determination of ovarian reserve in early breast cancer patients. Endocr Relat Cancer 2014; 21: R51-65. (PMID: 24292601) [CrossRef]

22. Wallace WH, Thomson AB, Kelsey TW. The radiosensivity of the human oocyte. Hum Reprod 2003; 18: 117-121. (PMID: 12525451) [CrossRef]
23. Anderson RA, Cameron DA. Pretreatment serum anti-müllerian hormone predicts long-term ovarian function and bone mass after chemotherapy for early breast cancer. J Clin Endocrinol Metab 2011; 96: 13361343 (PMID: 21325458) [CrossRef]

24. Ruddy KJ, Partridge AH. Fertility (male and female) and menopause. J Clin Oncol 2012; 30: 3705-3711. (PMID: 23008319) [CrossRef]

25. Wenners A, Grambach J, Koss J, Maass N, Jonat W, Schmutzler A, Mundhenke C. Reduced ovarian reserve in young early breast cancer patients: preliminary data from a prospective cohort trial. BMC Cancer 2017; 17: 632. (PMID: 28877720) [CrossRef] 